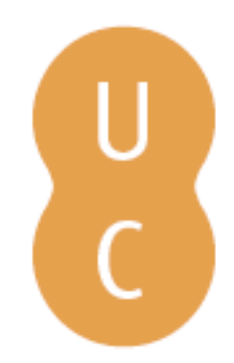

\title{
pommalina
}

\section{Enxurradas violentas após incêndios florestais: o exemplo de praias e piscinas fluviais da bacia do Rio Alva (Portugal)}

Autor(es): $\quad$ Lourenço, Luciano; Nunes, Adélia; Gonçalves, Joana

Publicado por: Imprensa da Universidade de Coimbra; RISCOS - Associação

URL persistente:

Portuguesa de Riscos, Prevenção e Segurança

DOI: $\quad$ DOI:http://dx.doi.org/10.14195/978-989-96253-3-4_121

Accessed : $\quad$ 26-Apr-2023 10:06:42

A navegação consulta e descarregamento dos títulos inseridos nas Bibliotecas Digitais UC Digitalis, UC Pombalina e UC Impactum, pressupõem a aceitação plena e sem reservas dos Termos e Condições de Uso destas Bibliotecas Digitais, disponíveis em https://digitalis.uc.pt/pt-pt/termos.

Conforme exposto nos referidos Termos e Condições de Uso, o descarregamento de títulos de acesso restrito requer uma licença válida de autorização devendo o utilizador aceder ao(s) documento(s) a partir de um endereço de IP da instituição detentora da supramencionada licença.

Ao utilizador é apenas permitido o descarregamento para uso pessoal, pelo que o emprego do(s) título(s) descarregado(s) para outro fim, designadamente comercial, carece de autorização do respetivo autor ou editor da obra.

Na medida em que todas as obras da UC Digitalis se encontram protegidas pelo Código do Direito de Autor e Direitos Conexos e demais legislação aplicável, toda a cópia, parcial ou total, deste documento, nos casos em que é legalmente admitida, deverá conter ou fazer-se acompanhar por este aviso. 

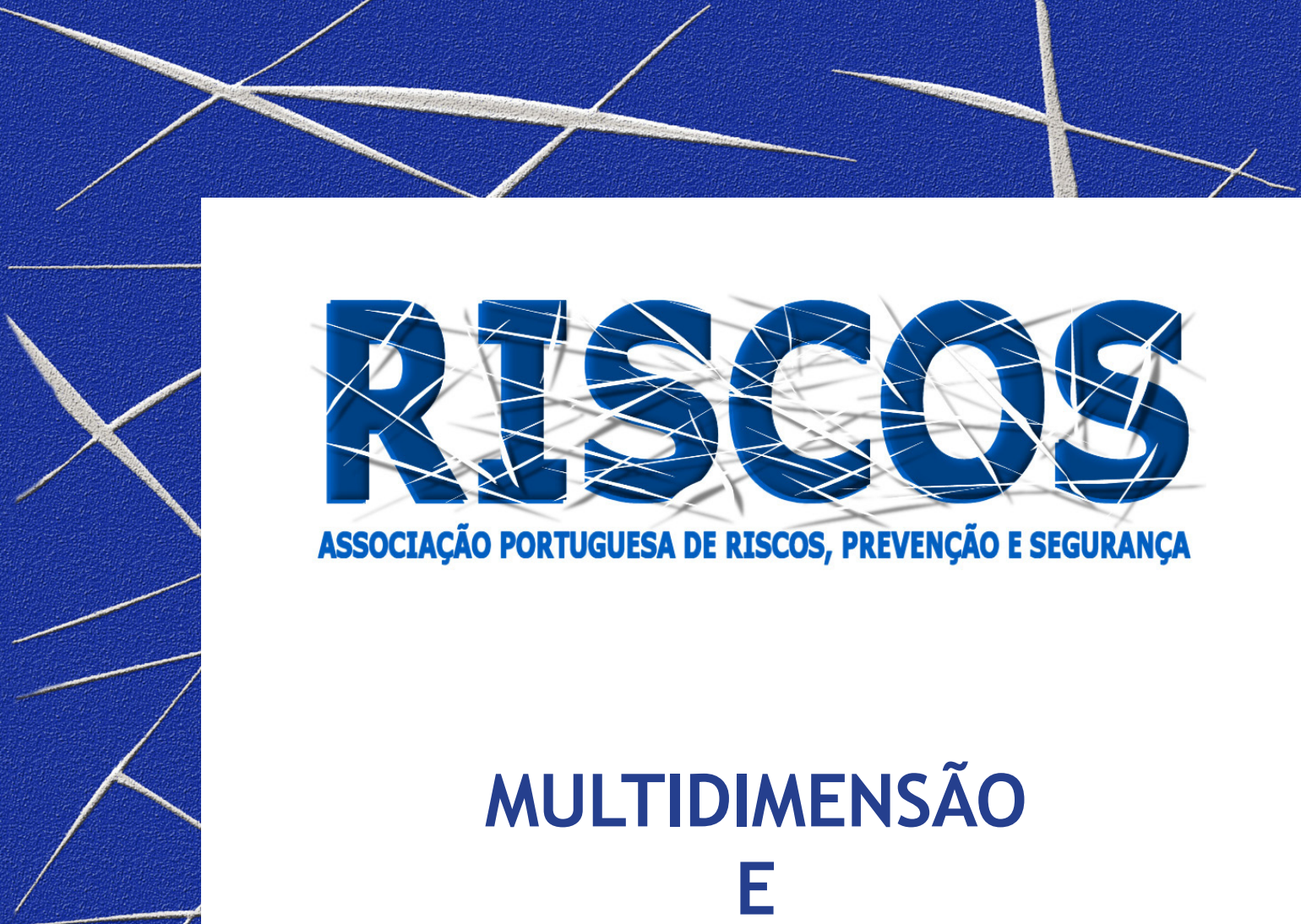

ASSOCIAÇÃO PORTUGUESA DE RISCOS, PREVENCCÃO E SEGURANÇA

MULTIDIMENSÃO

E
TERRITÓRIOS DE RISCO

III Congresso Internacional

I Simpósio Ibero-Americano

VIII Encontro Nacional de Riscos

Guimarães

2014 


\title{
ENXURRADAS VIOLENTAS APÓS INCÊNDIOS FLORESTAIS. O EXEMPLO DE PRAIAS E PISCINAS FLUVIAIS DA BACIA DO RIO ALVA (PORTUGAL)
}

\author{
Luciano Lourenço \\ Departamento de Geografia e CEGOT, Faculdade de Letras, Universidade de Coimbra \\ luciano@uc.pt \\ Adélia Nunes \\ Departamento de Geografia e CEGOT, Faculdade de Letras, Universidade de Coimbra \\ adelia.nunes@fl.uc.pt \\ Joana Gonçalves \\ NICIF, Faculdade de Letras, Universidade de Coimbra \\ jhuanita_rita@hotmail.com
}

\begin{abstract}
RESUMO
Partindo da análise da incidência e recorrência de incêndios florestais na bacia do rio Alva, descrevem-se alguns eventos violentos ocorridos na sua sequência, cuja resposta, tanto ao nível hidrológico como erosivo, afetou áreas muito para além dos limites das áreas queimadas. Procura-se, assim, inferir a importância que a destruição do coberto vegetal, conjugada com a ocorrência de chuvas intensas, pode ter no desencadear ou na intensificação de processos hidrogeomorfológicos (cheias, inundações e erosão de solos), tanto a seguir ao incêndio, como alguns meses após a sua ocorrência. A análise de vários eventos, que se manifestaram por enxurradas violentas, mostra que a suscetibilidade à manifestação dos riscos anteriormente referidos ocorre sobretudo na chamada ribeira de Alva, a montante da confluência com o rio Alvoco, bem como em duas outras sub-bacias, a de Pomares, situada ligeiramente a jusante dessa confluência, e a do Piódão, afluente do rio Avoco.
\end{abstract}

Palavras-chaves: Incêndios florestais, Cheias e inundação; Erosão de solos; Bacia do Rio Alva, Portugal.

\section{Introdução}

Vastas áreas do território continental português têm sido afetadas por incêndios florestais, nestas últimas décadas. A bacia hidrográfica do rio Alva, por integrar amplos territórios serranos, do Açor e da Estrela, tem sido severamente afetada pelas chamas, sobretudo depois de 1975. Com a destruição do coberto vegetal pelo fogo, o solo fica exposto ao impacte direto das gotas de chuva e a sua capacidade de retenção e armazenamento de água reduz-se, devido à perda de matéria orgânica do solo, à diminuição da porosidade e ao aumento de substâncias hidrofóbicas, gerando-se assim quantidades de escorrência muito maiores (Nunes et al., 2011/2; Prats et al., 2013), as quais influenciam o caudal de base e as pontas de cheia nos cursos de água (Ferreira et al., 2008), assim como diferentes intensidades nos processos erosivos.

Com o presente trabalho pretendem-se analisar alguns eventos severos ocorridos na bacia do rio Alva, na sequência de incêndios florestais, cujas implicações, tanto ao nível da resposta hidrológica como erosiva, não se limitaram à área percorrida pelas chamas, mas afetaram áreas muito para além dos perímetros dos incêndios. Por serem as que registaram maior recorrência não só de grandes incêndios florestais, mas também de manifestações hidrogeomorfológicas, dar-se-á particular ênfase às situações assinaladas nas bacias hidrográficas das ribeiras de Alva, Pomares e do Piódão, bem como do rio Alvoco e, em particular, às suas praias e piscinas fluviais. 
A bacia hidrográfica do rio Alva: localização, incidência e recorrência de incêndios Com uma área de aproximadamente $705 \mathrm{~km}^{2}$, a bacia hidrográfica do rio Alva, assinala um gradiente altimétrico superior a $1900 \mathrm{~m}$ (fig. 1). Com uma forma alongada, é no Alva superior que se situam algumas das suas mais importantes sub-bacias, bem como a jusante, na margem esquerda, designadamente as das ribeiras de Pomares, Coja e Folques (Lourenço,1986).

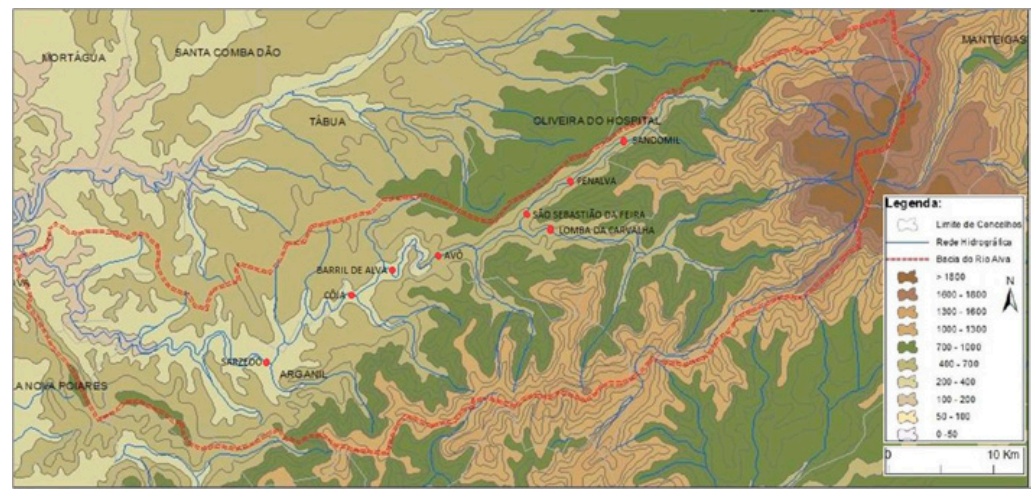

Fig. 1 - Localização da bacia hidrográfica do rio Alva e seu enquadramento hipsométrico

(Fonte: J. Gonçalves, 2013).

Tendo por base os incêndios com dimensão superior a 10 hectares, no período compreendido entre 1974 e 2013, sobressai não só a vastidão das áreas ardidas (fig. 2), as quais perfazem cerca de 77000 ha, mas também a reincidência de incêndios florestais, em especial nas bacias hidrográficas das ribeiras de Pomares e Piódão, com algumas áreas, durante este período, a arderam 6 vezes, como é disso exemplo o Monte do Colcurinho, e várias outras a serem incineradas cinco, quatro, três ou duas vezes (Lourenço e Nunes, 2014). Esta recorrência na incidência espacial de incêndios florestais mostra bem a suscetibilidade das áreas mais montanhosas da bacia do Alva à plena manifestação deste risco.

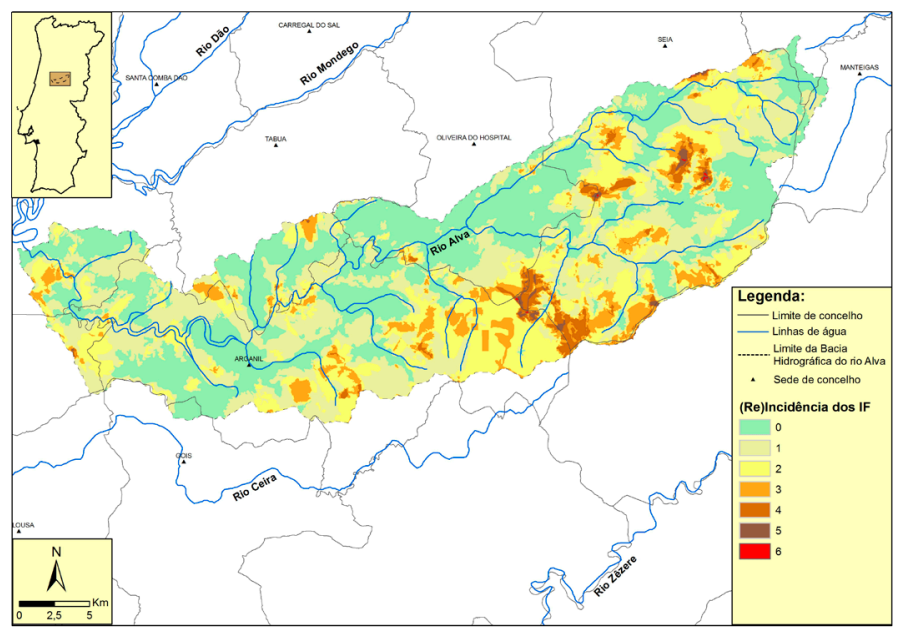

Fig. 2 - Áreas percorridas pelas chamas uma ou mais vezes, na bacia hidrográfica do rio Alva, no período de 1975 e 2013 (Fonte: Lourenço e Nunes, 2014, p. 51). 
No período analisado destacam-se alguns anos, em particular os de 1987 e 2005, como tendo sido dos mais flagelados pelas chamas. Em ambos, grande parte da área ardida deveu-se a um único incêndio, de grandes dimensões: o primeiro decorreu entre 13 e 20 de setembro de 1987, designado por incêndio de Arganil/Oliveira do Hospital, tendo devastado 10900 ha (Viegas et al., 1988); o segundo deflagrou entre 19 e 24 de julho de 2005 e percorreu mais de 15800 ha (Lourenço, 2007). Estes dois incêndios lavraram vastos territórios do Alva, com especial incidência nas bacias de Pomares e do Piódão. Os anos de 1990, 1992, 2010 e 2012 também registaram vastas áreas ardidas, superiores a 4000 ha, sendo que os 2 últimos afetaram sobretudo as cabeceiras do rio Alva.

Depois das chamas, a recorrência de enxurradas violentas

Analisam-se, na sequência de grandes incêndios florestais, vários episódios pluviosos cuja intensidade, decorrente da concentração temporal e espacial, estiveram na origem de violentas enxurradas, que acabaram por afetar áreas muito além das percorridas pelos incêndios florestais.

\section{A enxurrada de 23 de Junho de 1988 na ribeira de Pomares}

Na sequência de quantitativos de precipitação elevados, que ultrapassaram $70 \mathrm{~mm}$ no posto de Arganil, tanto no dia 21 como no dia 23, foi precisamente no dia 23 de Junho de 1988, cerca de 8 meses após o grande incêndio de setembro de 1987, que as consequências hidrológicas e erosivas se vieram a demonstrar mais desastrosas. Os elevados quantitativos de precipitação, intensificados pelo efeito orográfico, pela incidência localizada e pela precipitação antecedente, afetaram em especial as cabeceiras das ribeiras do Espinho e da Sorgaçosa, subafluentes da ribeira de Pomares. As intensas chuvas associadas à destruição da vegetação pelo fogo, tiveram um impacte direto no volume dos caudais das ribeiras da área atingida, afetando com particular violência a aldeia da Sorgaçosa, onde a rotura de diques, a montante, conduziu as águas correntes para as antigas linhas de água, tendo destruído campos de cultura, danificado uma casa e deixado intransitável o largo da aldeia (Lourenço, 1988).

\section{As enxurradas de 16 de Junho de 2006 nas bacias de Piódão e Pomares}

No dia 16 de Junho de 2006, cerca de um ano após o incêndio de julho de 2005, ocorreu um episódio pluviométrico que originou severos prejuízos materiais e humanos, quer nas cabeceiras, quer nos vales localizados a jusante, não só em consequência da cheia e inundação mas também e sobretudo por causa da grande quantidade de materiais carreados (Lourenço e Nunes, 2014).

Dos $58 \mathrm{~mm}$ de precipitação registados no Piódão, em junho, 50\% concentraram-se no dia 16 de Junho, sendo que $22 \mathrm{~mm}$ ocorreram entre as 17:00-18:00 h. Esta forte concentração espáciotemporal intensificou a atuação dos processos erosivos nas vertentes percorridas pelas chamas, tendo originado pontas de cheia nas ribeiras do Piódão e de Pomares e, depois, nos rios Alvoco e Alva, que, por isso, registaram inundações, sendo sobretudo afetadas as infraestruturas constituídas pelas piscinas e praias fluviais (Lourenço e Nunes, 2014).

\section{A enxurrada de 14 de Julho de 2006 na bacia de Piódão}

Cerca de um mês após o evento antes descrito, o cenário parece repetir-se e dotar-se ainda de maior violência, sobretudo na pequena bacia da ribeira do Piódão. De facto, o episódio pluvioso 
do dia 14 de Julho foi mais concentrado e intenso do que o anterior, afetando sobretudo as cabeceiras da ribeira do Piódão (Pereira e Lourenço, 2007). A chuva aí registada no mês de Julho foi superior à de Junho, totalizando $95 \mathrm{~mm}$. Todavia $70 \mathrm{~mm}$ caíram nos dias 13 e $14 \mathrm{de}$ julho, respetivamente com 30 e 39 milímetros. A precipitação do dia 14 de Julho concentrou-se num único evento, que ocorreu entre as 16:00h e as 17:00h, com $14 \mathrm{~mm}$, nos primeiros 30m, e $24 \mathrm{~mm}$, na meia hora seguinte.

A elevada intensidade horária da precipitação desencadeou uma rápida resposta da ribeira do Piódão e a ocorrência de um pico de cheia, com consequências bastante graves, não só devido às inundações que provocou mas também devido à capacidade e competência desta linha no transporte de inertes. Neste segundo episódio, a piscina ficou completamente soterrada por já ter as comportas colocadas. Contudo, a maior diferença entre este episódio e o do mês anterior foi a perda de uma vida humana. Apanhado desprevenido pela tempestade e pela torrente que se gerou na ribeira, um transeunte foi arrastado pela ponta de cheia, tendo sucumbido e ficado soterrado.

\section{A enxurrada de 31 de Agosto de 2010 no fosso do médio Alva}

Em meados de Agosto de 2010, um violento incêndio percorreu cerca 4300ha com a maior parte da área ardida localizada na bacia do rio Alva. Na sequência desse incêndio, no dia 31 de Agosto e após um intenso episódio pluvioso, a resposta hidrológica das pequenas ribeiras foi imediata. Dados recolhidos no posto de Oliveira do Hospital mostram que ocorreram cerca de $42 \mathrm{~mm}$ de precipitação, 31,2 mm dos quais entre as 15:00 e as 16:00h. A quantidade de chuva, caída num curto período de tempo e muito provavelmente intensificada pelo efeito orográfico do relevo serrano, desencadeou um intenso escoamento superficial, que rapidamente engrossou o caudal e gerou fluxos torrenciais em muitas das pequenas linhas de água afluentes do rio Alva.

Com o caudal foram transportados inertes vegetais deixados pela passagem do fogo mas também grandes quantidades de partículas minerais e cinzas. No rio Alva, além do aumento instantâneo do caudal, a tonalidade das águas indiciava a enorme quantidade de cinza e partículas de pequena dimensão, tendo contaminado a captação de água da Senhora do Desterro, feita para abastecimento da população dos concelhos de Seia, Gouveia e Oliveira do Hospital, bem como afetou diversas infraestruturas situadas a jusante, designadamente praias e piscinas fluviais.

\section{Conclusão}

A bacia do rio Alva emerge como um exemplo paradigmático onde se conjugam condições para a ocorrência recorrente de incêndios florestais, geralmente de grande dimensão, e, na sua sequência, para a manifestação de outros riscos, nomeadamente de cariz hidrológico, através de cheias e inundações, e de natureza geomorfológica, traduzida pela intensificação dos processos erosivos. A suscetibilidade à manifestação dos riscos anteriormente referidos parece ocorrer sobretudo no Alva Superior, a montante da confluência do Alvoco, bem como em duas outras sub-bacias, a de Pomares, situada ligeiramente a jusante dessa confluência, e a o Piódão, afluente ao rio Avoco.

Depois do flagelo das chamas, é sobretudo a ocorrência de elevados quantitativos de precipitação, quase sempre localizados e intensos, que agravam substancialmente os riscos de erosão pós-incêndio e estão na génese de outros fenómenos mais extremos, tais como fluxos de detritos, cheias e inundações após incêndios. 
Há, portanto, necessidade de implementar medidas que visem não só a redução das áreas ardidas, mas também o desenvolvimento de métodos e ferramentas para identificar e quantificar os riscos inerentes às inundações e ao transporte de detritos gerados na sequência dos incêndios, assim como para melhorar as previsões da magnitude e recorrência destes fenómenos ao nível da bacia hidrográfica.

\section{Bibliografia}

Ferreira, A. J. D.; Coelho, C. O. A.; Ritsema, C. J.; Boulet, A. K. e Keizer, J. J. (2008) - Soil and water degradation processes in burned areas: lessons learned from a nested approach, Catena, Vol. 74, p. 273-285.

Gonçalves, J. (2013) - Resposta fluvial a precipitações intensas/prolongadas após incêndios florestais. Exemplos da bacia hidrográfica do rio Alva. Dissertação de Mestrado em Geografia Física, em Ambiente e Ordenamento do Território, apresentada ao Departamento de Geografia, da Faculdade de Letras da Universidade de Coimbra, $100 \mathrm{p}$

Lourenço, L. (1986) - O Rio Alva: Hidrogeologia, Geomorfologia, Climatologia e Hidrologia. Instituto de Estudos Geográficos, Faculdade de Letras, Coimbra, 162 p.

Lourenço, L. (1988) - Lourenço, Luciano (1988) - Efeitos do temporal de 23 de Junho de 1988 na intensificação da erosão das vertentes afectadas pelo incêndio florestal de Arganil/Oliveira do Hospital, em Comunicações e Conclusões, Seminário Técnico sobre Parques e Conservação da Natureza nos Países do Sul da Europa, Faro, p. 43-77.

Lourenço, L. (2007) - Incêndios florestais de 2003 e 2005. Tão perto no tempo e já tão longe na memória!, em Riscos Ambientais e Formação de Professores, Núcleo de Investigação Científica de Incêndios Florestais da Faculdade de Letras da Universidade de Coimbra, Coimbra, p. 19-91.

Lourenço, L. e Nunes, A. (2014) - O flagelo das chamas e a recorrência de eventos hidrogeomorfológicos intensos. O exemplo da bacia do rio Alva (Portugal). Waterlat-Gobacit Network, Working Paper, "Water-related disasters: from trans-scale challenges to interpretative multivocality", Vol. 1 No 1 , p. 43-90.

Nunes, A., Lourenço, L., Vieira, A., Bento-Gonçalves, A. (2011-12) - 'Self-prevention': uma estratégia de prevenção de incêndios florestais na raia Ibérica. Cadernos de Geografia, 30/31, Faculdade de Letras, Coimbra, p. 99-106.

Oliveira, S. L. J. (2008) - Análise da frequência do fogo em Portugal Continental (1975-2005) com a distribuição de Weibull, Tese de mestrado, ISA, UTL, Lisboa, Portugal.

Oliveira, S. L. J.; Pereira, José M. C. e Carreiras, João M. B. (2011) - Fire frequency analysis in Portugal (1975-2005), using Landsat-based burnt area maps. International. Journal of Wildland Fire, 21(1) p. 48-60.

Pereira, N. e Lourenço, L. (2007) - Riscos de cheias e inundações após incêndios florestais. O exemplo das bacias hidrográficas das ribeiras do Piódão e Pomares, em Riscos Ambientais e Formação de Professores. Núcleo de Investigação Científica de Incêndios Florestais da Faculdade de Letras da Universidade de Coimbra, Coimbra, p. 123-149.

Prats, S. A.; Malvar, M.C.; Vieira, D. C. S.; Macdonald, L.; Keizer J.J. (2013) - Effectiveness of hydromulching to reduce runoff and erosion in a recently burnt pine plantation in central Portugal. Land Degradation \& Development. DOI: 10.1002/ldr.2236.

Viegas, D. X.; Lourenço, L.; Neto, L.; Monteiro, J. Paiva; Pais, T.; Reis, J.; Ferreira, A. e Goulão, M. (1988) Análise do Incêndio Florestal ocorrido em Arganil/Oliveira do Hospital de 13 a 20 de Setembro de 1987. Centro de Mecânica dos Fluidos, Coimbra, 102 p.; 